\title{
FIXED POINTS AND ITERATION OF A NONEXPANSIVE MAPPING IN A BANACH SPACE
}

\author{
SHIRO ISHIKAWA
}

\begin{abstract}
The following result is shown. If $T$ is a nonexpansive mapping from a closed convex subset $D$ of a Banach space into a compact subset of $D$ and $x_{1}$ is any point in $D$, then the sequence $\left\{x_{n}\right\}$ defined by $x_{n+1}$ $=2^{-1}\left(x_{n}+T x_{n}\right)$ converges to a fixed point of $T$. As a matter of fact, a theorem which includes this result is proved. Furthermore, a similar result is obtained under certain restrictions which do not imply the assumption on the compactness of $T$.
\end{abstract}

Throughout this paper we consider the following iterative procedure, which is a special case of the generalized iteration method introduced by $W$. R. Mann [7].

Definition. If $D$ is a subset of a Banach space $X, T$ is a mapping from $D$ into $X$, and $x_{1} \in D$, then $M\left(x_{1}, t_{n}, T\right)$ is the sequence $\left\{x_{n}\right\}_{n=1}^{\infty}$ defined by $x_{n+1}=\left(1-t_{n}\right) x_{n}+t_{n} T x_{n}$, where $\left\{t_{n}\right\}_{n=1}^{\infty}$ is a real sequence. If a point $x_{1}$ and a sequence $\left\{t_{n}\right\}_{n=1}^{\infty}$ satisfy the following three conditions:

$$
\begin{gathered}
\sum_{n=1}^{\infty} t_{n}=\infty, \\
0 \leqslant t_{n} \leqslant b<1 \quad \text { for all positive integers } n,
\end{gathered}
$$

and

$$
x_{n} \in D \text { for all positive integers } n,
$$

then $x_{1}$ and $\left\{t_{n}\right\}_{n=1}^{\infty}$ will be said to satisfy Condition A.

Note that if $t_{n} \in[a, b]$ for all positive integers $n$ and $0<a \leqslant b<1$, then it is obvious that the sequence $\left\{t_{n}\right\}_{n=1}^{\infty}$ satisfies (1) and (2).

These iteration methods have been investigated by Krasnosel'skii [6], Edelstein [3], Outlaw [9], Dotson [2] and others. They showed that these iterative methods may be used to find a fixed point of a nonexpansive mapping $T$ mainly in a uniformly convex Banach space or a strictly convex Banach space, where a mapping $T$ from a subset $D$ of a Banach space $X$ into $X$ is called a nonexpansive mapping if $T$ satisfies the condition that $\|T x-T y\|$ $\leqslant\|x-y\|$ for all $x, y \in D$.

In this paper we study the iterative method for nonexpansive mappings

Received by the editors August 8, 1975 and, in revised form, November 7, 1975. AMS (MOS) subject classifications (1970). Primary 47H10; Secondary 40A05.

Key words and phrases. Iteration method, nonexpansive mapping. 
without any assumption on convexity of the Banach space.

LEMMA 1. Let $\left\{s_{i}\right\}_{i=1}^{\infty}$ be a sequence in the real numbers and let $\left\{u_{i}\right\}_{i=1}^{\infty}$ be a sequence in a Banach space $X$. Then for any positive integer $N$,

$$
\begin{aligned}
& \left(\prod_{i=1}^{N-1} s_{i}\right)\left(\sum_{i=1}^{N}\left(1-s_{i}\right) u_{i}\right) \\
& \quad=\left(1-\prod_{i=1}^{N} s_{i}\right) u_{N}-\sum_{i=1}^{N-1}\left\{\left(\prod_{j=i+1}^{N-1} s_{j}\right)\left(1-\prod_{j=1}^{i} s_{j}\right)\left(u_{i+1}-s_{i} u_{i}\right)\right\} .
\end{aligned}
$$

If $X$ is the real line and $u_{i}=1$ for all $i$, we have the special case

$$
\begin{aligned}
& \left(\prod_{i=1}^{N-1} s_{i}\right)\left(\sum_{i=1}^{N}\left(1-s_{i}\right)\right) \\
& \quad=1-\prod_{i=1}^{N} s_{i}-\sum_{i=1}^{N-1}\left\{\left(\prod_{j=i+1}^{N-1} s_{j}\right)\left(1-\prod_{j=1}^{i} s_{j}\right)\left(1-s_{i}\right)\right\} .
\end{aligned}
$$

Here and hereafter we agree that $\sum_{i=m}^{n}$ and $\prod_{i=m}^{n}$ are defined to be 0 and 1 , respectively, for $n<m$.

Proof. When $N=1$, the result is trivial. Supposing that (3) is true for some $N \geqslant 1$, we have

$$
\begin{aligned}
\sum_{i=1}^{N}\left\{\left(\prod_{j=i+1}^{N} s_{j}\right)\left(1-\prod_{j=1}^{i} s_{j}\right)\left(u_{i+1}-s_{i} u_{i}\right)\right\} \\
=s_{N} \sum_{i=1}^{N-1}\left\{\left(\prod_{j=i+1}^{N-1} s_{j}\right)\left(1-\prod_{j=1}^{i} s_{j}\right)\left(u_{i+1}-s_{i} u_{i}\right)\right\} \\
-s_{N}\left(1-\prod_{i=1}^{N} s_{i}\right) u_{N}+\left(1-\prod_{i=1}^{N} s_{i}\right) u_{N+1} \\
=s_{N}\left\{\left(1-\prod_{i=1}^{N} s_{i}\right) u_{N}-\left(\prod_{i=1}^{N-1} s_{i}\right)\left(\sum_{i=1}^{N}\left(1-s_{i}\right) u_{i}\right)\right\} \\
\quad-s_{N}\left(1-\prod_{i=1}^{N} s_{i}\right) u_{N}+\left(1-\prod_{i=1}^{N} s_{i}\right) u_{N+1} \\
=-\left(\prod_{i=1}^{N} s_{i}\right)\left(\sum_{i=1}^{N}\left(1-s_{i}\right) u_{i}\right)+\left(1-\prod_{i=1}^{N} s_{i}\right) u_{N+1},
\end{aligned}
$$

from which it follows that

\{the right-hand side of (3) with $N+1$ for $N$ \}

$$
\begin{aligned}
& =\left(1-\prod_{i=1}^{N+1} s_{i}\right) u_{N+1}-\sum_{i=1}^{N}\left\{\left(\prod_{j=i+1}^{N} s_{j}\right)\left(1-\prod_{j=1}^{i} s_{j}\right)\left(u_{i+1}-s_{i} u_{i}\right)\right\} \\
& =\left(1-s_{N+1} \prod_{i=1}^{N} s_{i}\right) u_{N+1}+\left(\prod_{i=1}^{N} s_{i}\right)\left(\sum_{i=1}^{N}\left(1-s_{i}\right) u_{i}\right)-\left(1-\prod_{i=1}^{N} s_{i}\right) u_{N+1} \\
& =\left(\prod_{i=1}^{N} s_{i}\right)\left(\sum_{i=1}^{N+1}\left(1-s_{i}\right) u_{i}\right) .
\end{aligned}
$$


By induction this completes the proof.

LEMMA 2. Let $D$ be a subset of a Banach space $X$ and let $T$ be a nonexpansive mapping from $D$ into $X$. If there exist $x_{1}$ and $\left\{t_{n}\right\}_{n=1}^{\infty}$ that satisfy Condition $\mathrm{A}$ and $M\left(x_{1}, t_{n}, T\right)$ is bounded, then $x_{n}-T x_{n}$ converges to zero as $n \rightarrow \infty$.

Proof. Since $T$ is a nonexpansive mapping, we have

$$
\begin{aligned}
\left\|x_{n+1}-T x_{n+1}\right\| & =\left\|\left(1-t_{n}\right) x_{n}+t_{n} T x_{n}-T x_{n+1}\right\| \\
& =\left\|\left(1-t_{n}\right)\left(x_{n}-T x_{n}\right)+T x_{n}-T x_{n+1}\right\| \\
& \leqslant\left(1-t_{n}\right)\left\|x_{n}-T x_{n}\right\|+\left\|x_{n}-x_{n+1}\right\| \\
& =\left(1-t_{n}\right)\left\|x_{n}-T x_{n}\right\|+\left\|x_{n}-\left(\left(1-t_{n}\right) x_{n}+t_{n} T x_{n}\right)\right\| \\
& =\left\|x_{n}-T x_{n}\right\| .
\end{aligned}
$$

Thus the sequence $\left\{\left\|x_{n}-T x_{n}\right\|\right\}_{n=1}^{\infty}$ is nonincreasing and bounded below, so $\lim _{n \rightarrow \infty}\left\|x_{n}-T x_{n}\right\|$ exists.

Suppose that $\lim _{n \rightarrow \infty}\left\|x_{n}-T x_{n}\right\|=r>0$. That is, for any $\varepsilon>0$, there exists an integer $m$ such that

$$
r \leqslant\left\|x_{m+i}-T x_{m+i}\right\| \leqslant(1+\varepsilon) r \text { for all positive integers } i \text {. }
$$

Then since $T$ is nonexpansive,

$$
\begin{aligned}
& \left\|\left(T x_{m+i+1}-x_{m+i+1}\right)-\left(1-t_{m+i}\right)\left(T x_{m+i}-x_{m+i}\right)\right\| \\
& =\| T\left(\left(1-t_{m+i}\right) x_{m+i}+t_{m+i} T x_{m+i}\right) \\
& \quad-\left(\left(1-t_{m+i}\right) x_{m+i}+t_{m+i} T x_{m+i}\right)-\left(1-t_{m+i}\right)\left(T x_{m+i}-x_{m+i}\right) \| \\
& =\left\|T\left(\left(1-t_{m+i}\right) x_{m+i}+t_{m+i} T x_{m+i}\right)-T x_{m+i}\right\| \\
& \leqslant t_{m+i}\left\|x_{m+i}-T x_{m+i}\right\| \leqslant t_{m+i}(1+\varepsilon) r .
\end{aligned}
$$

Since $\left\{x_{n}\right\}_{n=1}^{\infty}$ is bounded and $\left\{t_{n}\right\}_{n=1}^{\infty}$ satisfies condition (1), there exists an integer $N$ such that

$$
r \sum_{i=1}^{N-1} t_{m+i} \leqslant \delta(M)+1 \leqslant r \sum_{i=1}^{N} t_{m+i}
$$

where $\delta(M)$ is defined by $\sup \left\{\left\|x_{i}-x_{j}\right\| ; 0<i, j<\infty\right\}$.

Now setting $s_{i}=1-t_{m+i}$ and $u_{i}=T x_{m+i}-x_{m+i}$ for all positive integers $i$, we get from (6),

$$
\begin{aligned}
\left\|u_{i+1}-s_{i} u_{i}\right\| & =\left\|T x_{m+i+1}-x_{m+i+1}-\left(1-t_{m+i}\right)\left(T x_{m+i}-x_{m+i}\right)\right\| \\
& \leqslant t_{m+i}(1+\varepsilon) r=\left(1-s_{i}\right)(1+\varepsilon) r
\end{aligned}
$$

and

$$
\begin{aligned}
x_{m+N+1}-x_{m+1} & =\sum_{i=1}^{N}\left\{\left(\left(1-t_{m+i}\right) x_{m+i}+t_{m+i} T x_{m+i}\right)-x_{m+i}\right\} \\
& =\sum_{i=1}^{N} t_{m+i}\left(T x_{m+i}-x_{m+i}\right)=\sum_{i=1}^{N}\left(1-s_{i}\right) u_{i} .
\end{aligned}
$$


Thus using Lemma 1, we have from (9), (3), (5) and (8) that

$$
\begin{aligned}
\left(\prod_{i=1}^{N-1} s_{i}\right)\left\|x_{m+N+1}-x_{m+1}\right\|=\left\|\left(\prod_{i=1}^{N-1} s_{i}\right)\left(\sum_{i=1}^{N}\left(1-s_{i}\right) u_{i}\right)\right\| & \\
\geqslant & \left(1-\prod_{i=1}^{N} s_{i}\right)\left\|u_{N}\right\|-\sum_{i=1}^{N-1}\left\{\left(\prod_{j=i+1}^{N-1} s_{j}\right)\left(1-\prod_{j=1}^{i} s_{j}\right)\left\|u_{i+1}-s_{i} u_{i}\right\|\right\} \\
\geqslant & \left(1-\prod_{i=1}^{N} s_{i}\right) r-\sum_{i=1}^{N-1}\left\{\left(\prod_{j=i+1}^{N-1} s_{j}\right)\left(1-\prod_{j=1}^{i} s_{j}\right)\left(1-s_{i}\right)(1+\varepsilon) r\right\} \\
= & {\left[1-\prod_{i=1}^{N} s_{i}-\sum_{i=1}^{N-1}\left\{\left(\prod_{j=i+1}^{N-1} s_{j}\right)\left(1-\prod_{j=1}^{i} s_{j}\right)\left(1-s_{i}\right)\right\}\right] r } \\
& \quad-\varepsilon r \sum_{i=1}^{N-1}\left\{\left(\prod_{j=i+1}^{N-1} s_{j}\right)\left(1-\prod_{j=1}^{i} s_{j}\right)\left(1-s_{i}\right)\right\},
\end{aligned}
$$

since $s_{i}=1-t_{m+i} \geqslant 1-b>0$, which implies from (4) and (7) that

$$
\begin{aligned}
\left\|x_{m+N+1}-x_{m+1}\right\| \geqslant & r \sum_{i=1}^{N}\left(1-s_{i}\right)-\varepsilon r\left(\prod_{i=1}^{N-1} s_{i}\right)^{-1} \\
& \times\left\{1-\prod_{i=1}^{N} s_{i}-\left(\prod_{i=1}^{N-1} s_{i}\right)\left(\sum_{i=1}^{N}\left(1-s_{i}\right)\right)\right\} \\
\geqslant & r \sum_{i=1}^{N}\left(1-s_{i}\right)-\varepsilon r\left(\prod_{i=1}^{N-1} s_{i}\right)^{-1} \\
= & r \sum_{i=1}^{N} t_{m+i}-\varepsilon r \prod_{i=1}^{N-1}\left(1-t_{m+i}\right)^{-1} \\
\geqslant & \delta(M)+1-\varepsilon r \prod_{i=1}^{N-1}\left(1-t_{m+i}\right)^{-1} .
\end{aligned}
$$

Since $\log (1+y) \leqslant y$ for any $y \in(-1, \infty)$, we have from (2) and (7),

$$
\begin{aligned}
\prod_{i=1}^{N-1}\left(1-t_{m+i}\right)^{-1} & =\prod_{i=1}^{N-1}\left(1+t_{m+i}\left(1-t_{m+i}\right)^{-1}\right) \\
& =\exp \left\{\sum_{i=1}^{N-1} \log \left(1+t_{m+i}\left(1-t_{m+i}\right)^{-1}\right)\right\} \\
& \leqslant \exp \left\{\sum_{i=1}^{N-1} t_{m+i}\left(1-t_{m+i}\right)^{-1}\right\} \\
& \leqslant \exp \left\{(1-b)^{-1} \sum_{i=1}^{N-1} t_{m+i}\right\} \\
& \leqslant \exp \left\{(1-b)^{-1}(\delta(M)+1) r^{-1}\right\} .
\end{aligned}
$$

From this and (10) we get that

$$
\begin{gathered}
\delta(M)+1-\varepsilon r \exp \left\{(1-b)^{-1}(\delta(M)+1) r^{-1}\right\} \\
\leqslant\left\|x_{m+N+1}-x_{m+1}\right\| \leqslant \delta(M) .
\end{gathered}
$$


Since $\varepsilon$ is an arbitrary positive number, it follows that $\delta(M)+1 \leqslant \delta(M)$. This contradiction completes the proof.

REMARK. Let $T$ be a nonexpansive mapping from a convex set $D$ in a Banach space into a bounded subset of $D$ and let $(1-t) I+t T$ be denoted by $T_{t}$, where $I$ is an identity map and $0<t<1$. Then $M\left(x_{1}, t, T\right)$ is bounded since it is a sequence in the convex hull of the union of $T(D)$ and the point $x_{1}$. Also it is clear that $T_{t}^{n} x_{1}-T_{t}^{n-1} x_{1}=t\left(T x_{n}-x_{n}\right)$. Therefore we have by Lemma 2 that $T_{t}$ is asymptotically regular (i.e. for any $x \in D, \| T_{t}^{n+1} x$ $-T_{t}^{n} x \| \rightarrow 0$ as $\left.n \rightarrow \infty\right)$.

Fixed points and iterative process for compact mappings. Now we shall prove a fixed point theorem for a nonexpansive compact mapping and show that the iterative process $M\left(x_{1}, t_{n}, T\right)$ may be used to find the fixed point.

THEOREM 1. Let $D$ be a closed subset of a Banach space $X$ and let $T$ be $a$ nonexpansive mapping from $D$ into a compact subset of $X$. If there exist $x_{1}$ and $\left\{t_{n}\right\}_{n=1}^{\infty}$ that satisfy Condition $\mathrm{A}$, then $T$ has a fixed point in $D$ and $M\left(x_{1}, t_{n}, T\right)$ converges to a fixed point of $T$.

Proof. Let $D_{0}$ denote the closure of the convex hull of the union of $T(D)$ and the point $x_{1}$. A well-known theorem of Mazur implies that $D_{0}$ is compact. The sequence $M\left(x_{1}, t_{n}, T\right)$ clearly belongs to $D_{0}$. From this and Condition $\mathrm{A}$, it immediately follows that $\left\{x_{n}\right\}_{n=1}^{\infty}$ is a compact sequence in $D$. Hence there is a subsequence $\left\{x_{n_{i}}\right\}_{i=1}^{\infty}$ that converges to a point $u$, which obviously belongs to $D$ since $D$ is closed. And it is clear that $\lim _{i \rightarrow \infty}\left\|T x_{n_{i}}-x_{n_{i}}\right\|=0$ since Lemma 2 is applicable from the boundedness of $D_{0}$.

Now since $T$ is nonexpansive,

$$
\begin{aligned}
\|T u-u\| & =\left\|T u-T x_{n_{i}}+T x_{n_{i}}-x_{n_{i}}+x_{n_{i}}-u\right\| \\
& \leqslant 2\left\|u-x_{n_{i}}\right\|+\left\|T x_{n_{i}}-x_{n_{i}}\right\|,
\end{aligned}
$$

which implies that $u$ is a fixed point of $T$ since $\lim _{i \rightarrow \infty}\left\|u-x_{n_{i}}\right\|=0$ and $\lim _{i \rightarrow \infty}\left\|T x_{n_{i}}-x_{n_{i}}\right\|=0$.

Further,

$$
\begin{aligned}
\left\|x_{n+1}-u\right\| & =\left\|\left(1-t_{n}\right) x_{n}+t_{n} T x_{n}-u\right\| \\
& =\left\|\left(1-t_{n}\right)\left(x_{n}-u\right)+t_{n}\left(T x_{n}-T u\right)\right\| \leqslant\left\|x_{n}-u\right\|
\end{aligned}
$$

for any positive integer $n$. For any $\varepsilon>0$ there exists an integer $n_{0}$ such that $\left\|x_{n_{0}}-u\right\|<\varepsilon$, so we obtain from (11) that $\left\|x_{n}-u\right\|<\varepsilon$ for any integer $n \geqslant n_{0}$. Therefore $M\left(x_{1}, t_{n}, T\right)$ converges to $u$, a fixed point of $T$.

As an immediate consequence of Theorem 1, we have the following corollaries.

Corollary 1. Let $D$ be a closed subset of a Banach space $X$ and let $T$ be a nonexpansive mapping from $D$ into a compact subset of $X$. If there exists $t \in(0,1)$ such that $(1-t) x+t T x \in D$ for all $x \in D$, then $T$ has a fixed point in $D$ and for any $x_{1} \in D, M\left(x_{1}, t, T\right)$ converges to a fixed point of $T$.

Corollary 2. Let $D$ be a closed convex subset of a Banach space $X$ and let $T$ 
be a nonexpansive mapping from $D$ into a compact subset of $D$. Then $T$ has a fixed point in $D$ and $M\left(x_{1}, 2^{-1}, T\right)$ converges to a fixed point of $T$ for any $x_{1} \in D$.

Note that the first part of Corollary 2 is a special case of a fixed point theorem of Schauder.

Corollary 2 was proved for uniformly convex spaces by Krasnosel'skiī [6] and strictly convex spaces by Edelstein [3].

Fixed points and iterative process for noncompact mappings. Next we shall consider the iterative process for a nonexpansive mapping without the assumption on the compactness of $T$.

Let $D$ be a subset of a Banach space $X$. A mapping $T: D \rightarrow X$ with a nonempty fixed points set $F$ in $D$ will be said to satisfy Condition B if there is a nondecreasing function $f:[0, \infty) \rightarrow[0, \infty)$ with $f(0)=0, f(r)>0$ for $r \in(0, \infty)$, such that $\|x-T x\| \geqslant f(d(x, F))$ for all $x \in D$, where $d(x, F)$ $=\inf \{\|x-z\| ; z \in F\}$. This condition is due to Senter and Dotson [10].

Theorem 2. Let $D$ be a closed subset of a Banach space $X$ and let $T: D \rightarrow X$ be a nonexpansive mapping with a nonempty fixed points set $F$ in $D$. If $T$ satisfies Condition B and there exist $x_{1}$ and $\left\{t_{n}\right\}_{n=1}^{\infty}$ that satisfy Condition $\mathrm{A}$, then $M\left(x_{1}, t_{n}, T\right)$ converges to a member of $F$.

Proof. The theorem is trivial if $x_{1} \in F$, so we assume $x_{1} \in D-F$. For any $u \in F$ we have that $\left\|T x_{n}-u\right\| \leqslant\left\|x_{n}-u\right\|$ and so we get that

$$
\left\|x_{n+1}-u\right\|=\left\|\left(1-t_{n}\right) x_{n}+t_{n} T x_{n}-u\right\| \leqslant\left\|x_{n}-u\right\|
$$

which implies that $d\left(x_{n+1}, F\right) \leqslant d\left(x_{n}, F\right)$ for all positive integers $n$. The sequence $\left\{d\left(x_{n}, F\right)\right\}_{n=1}^{\infty}$ is nonincreasing and bounded below, so there exists $\lim _{n \rightarrow \infty} d\left(x_{n}, F\right)$, which we denote by $r$.

By the definition of $f$, we have

$$
\left\|x_{n}-T x_{n}\right\| \geqslant f\left(d\left(x_{n}, F\right)\right) \geqslant f(r) .
$$

Since it follows from (12) that $M\left(x_{1}, t_{n}, T\right)$ is a bounded sequence in $D$, we have from Lemma 2 and (13) that $f(r)=0$. Hence we get that

$$
\lim _{n \rightarrow \infty} d\left(x_{n}, F\right)=r=0 .
$$

Now we shall show that $M\left(x_{1}, t_{n}, T\right)$ converges to a member of $F$. Since $\lim _{n \rightarrow \infty} d\left(x_{n}, F\right)=0$, for any positive integer $i$ there exist $N_{i}>0$ and $u_{i} \in F$ such that $\left\|x_{N_{i}}-u_{i}\right\|<2^{-i}$, which implies from (12) that $\left\|x_{n}-u_{i}\right\|<2^{-i}$ for all $n \geqslant N_{i}$. We require $N_{i+1} \geqslant N_{i}$ for all $i>0$. Then we have that for any integers $i$ and $j$ such that $i<j$,

$$
\begin{aligned}
\left\|u_{i}-u_{j}\right\| \leqslant & \left\|u_{i}-x_{N_{i+1}}\right\|+\left\|x_{N_{i+1}}-u_{i+1}\right\|+\left\|u_{i+1}-x_{N_{i+2}}\right\| \\
& +\cdots+\left\|u_{j-1}-x_{N_{j}}\right\|+\left\|x_{N_{j}}-u_{j}\right\| \\
\leqslant & 2^{-i}+2^{-i-1}+2^{-i-1}+2^{-i-2}+\cdots+2^{-j+1}+2^{-j} \\
= & 3\left(2^{-i}-2^{-j}\right)
\end{aligned}
$$


which implies $\left\{u_{i}\right\}_{i=1}^{\infty}$ is a Cauchy sequence, so there exists $v$ such that $v=\lim _{i \rightarrow \infty} u_{i}$ and $v$ belongs to $F$ since $F$ is closed. For any $\varepsilon>0$ there exists $i_{0}>0$ such that $2^{-i_{0}}<2^{-1} \varepsilon$ and $\left\|u_{i_{0}}-v\right\|<2^{-1} \varepsilon$, so we have that

$\left\|x_{n}-v\right\| \leqslant\left\|x_{n}-u_{i_{0}}\right\|+\left\|u_{i_{0}}-v\right\| \leqslant 2^{-i_{0}}+\left\|u_{i_{0}}-v\right\|<\varepsilon$ for all $n>N_{i_{0}}$.

Therefore $M\left(x_{1}, t_{n}, T\right)$ converges to the point $v$ of $F$.

Corollary 3. Let $D$ be a closed convex subset of $X$ and let $T: D \rightarrow D$ be a nonexpansive mapping with a nonempty fixed points set $F$. If $T$ satisfies Condition $\mathrm{B}$, then for any $x_{1} \in D$ and any $\left\{t_{n}\right\}_{n=1}^{\infty}$ satisfying (1) and (2), $M\left(x_{1}, t_{n}, T\right)$ converges to a member of $F$.

If $X$ is a uniformly convex Banach space and $0<a \leqslant t_{n} \leqslant b<1$ for all integers $n>0$, the analog of this corollary was obtained by Senter and Dotson [10].

The author wishes to express his sincere thanks to Professor T. Kawata, Professor S. Koizumi and the referee for their valuable suggestions regarding the improvement of the paper.

\section{REFERENCES}

1. G. Darbo, Punti uniti in transformazioni a condominio non compatto, Rend. Sem. Mat. Univ. Padova 24 (1955), 84-92. MR 16, 1140.

2. W. G. Dotson, Jr., On the Mann iterative process, Trans. Amer. Math. Soc. 149 (1970), 65-73. MR 41 \#2477.

3. M. Edelstein, A remark on a theorem of M. A. Krasnoselski, Amer. Math. Monthly 73 (1966), 509-510. MR 33 \#3072.

4. G. W. Groetsch, A note on segmenting Mann iterates, J. Math. Anal. Appl. 40 (1972), 369-372. MR 49 \# 5954.

5. S. Ishikawa, Fixed points by a new iteration method, Proc. Amer. Math. Soc. 44 (1974), 147-150. MR 49 \# 1243.

6. M. A. Krasnosel'skiī, Two remarks on the method of successive approximations, Uspehi Mat. Nauk 10 (1955), no. 1 (63), 123-127. (Russian) MR 16, 833.

7. W. R. Mann, Mean value methods in iteration, Proc. Amer. Math. Soc. 4 (1953), 506-510. MR 14, 988.

8. R. D. Nussbaum, The fixed point index for local condensing maps, Ann. Mat. Pura. Appl. (4) 89 (1971), 213-258. MR 47 \#903.

9. C. L. Outlaw, Mean value iteration of nonexpansive mappings in a Banach space, Pacific J. Math. 30 (1969), 747-750. MR 40 \#807.

10. H. F. Senter and W. G. Dotson, Approximating fixed points of nonexpansive mappings, Proc. Amer. Math. Soc. 44 (1974), 375-380. MR 49 \#11333.

Faculty of Engineering, Department of Mathematics, Keio University, Yokohama, JAPAN 